\title{
JEAN-MARC-GASPARD ITARD, LEV SEMIONOVITCH VIGOTSKI E 0 DETERMINISMO BIOLÓGICO
}

\author{
JEAN-MARC-GASPARD ITARD, LEV SEMIONOVITCH VIGOTSKI AND \\ BIOLOGICAL DETERMINISM
}

JEAN-MARC-GASPARD ITARD, LEV SEMIONOVITCH VIGOTSKI Y
DETERMINISMO BIOLÓGICO

https://orcid.org/oooo-0oo2-6884-8521

Aline de Souza Pereira**

https://orcid.org/oooo-0oo1-8373-7048

\begin{abstract}
REVISTA PEDAGÓGICA
Revista do Programa de Pós-graduação em Educação da Unochapecó | ISSN 1984-1566 Universidade Comunitária da Região de Chapecó | Chapecó-SC, Brasil Como referenciar este artigo: TUNES, E.; PEREIRA, A. S. Jean-Marc-Gaspard Itard, Lev Semionovitch Vigotski e o determinismo biológico. Revista Pedagógica, Chapecó, v. 22, p. 1-14, 2020. DOI: http://dx.doi.org/10.22196/rp.v22io.4570
\end{abstract}

\begin{abstract}
Resumo: No presente ensaio, são apresentados alguns fatos históricos que, talvez, possam lançar alguma luz para a compreensão do hiato histórico que se verifica entre dois estudiosos que se ocuparam de questões ligadas à educação de crianças com deficiência, no passado. São eles: Jean-Mark-Gaspard Itard e Lev Semionovitch Vigotski. O primeiro nasceu no sul da França, em 1774; o segundo nasceu na Bielorrúsia em 1896. No presente texto, inicialmente, é feita uma síntese das principais ideias de cada autor acerca da educação e do desenvolvimento de crianças com deficiência, buscandose destacar aquelas que apresentam similaridades entre si. Em seguida, procura-se realizar uma caracterização do cenário científico que se desdobrou nesse intervalo de cento e vinte anos e suas principais relações com o contexto social maior da época, apontando-se para o que, talvez, possa estar na raiz do adormecimento histórico das concepções de Jean Itard, a saber, a hegemonia da doutrina do determinismo biológico.
\end{abstract}

Palavras-chave: Criança. Deficiência. Determinismo biológico. Itard. Vigotski.

Abstract: In this essay, some historical facts are presented that perhaps may shed some light on the understanding of the historical gape that exists between two scholars who have dealt with issues related to the education of children with disabilities. They are: JeanMar-Gaspard Itard and Lev Semionovitch Vigotski. The first was born in the south of France, in 1774; the second was born in Belarus in 1896. In the present text, initially, we made a synthesis of the main ideas of each author about the education and development of children with disabilities. We try to highlight ideas that present similarities with each other. Then, we seek to carry out a brief characterization of the scientific scenario that unfolds in this interval of 120 years and its main relations with the larger social context of that time, pointing out what, perhaps, may be the root of the historical forgetfulness of Jean Itard's conceptions, namely, the doctrine of biological determinism.

Keywords: Child. Deficiency. Biological Determinism. Itard. Vigotski.

Resumen: Em este ensayo, se presentan algunos hechos históricos que, tal vez, pueden arrojar algo de luz sobre la comprensión de la brecha histórica que existe entre dos académicos que han tratado temas relacionados con la educación de niños com discapacidades en el pasado. Ellos son Jean-Mark-Gaspard Itard y Lev Semionovitch Vigotski. El primero nació en el sur de Francia, em 1774; el segundo nació em Bielorrusia en 1896. En el presente texto, inicialmente, se hace una síntesis de las ideas principales de cada autor sobre la educación y el desarrollo de los niños con discapacidades, buscando resaltar aquellos que presentan similitudes entre sí. Luego, buscamos llevar a cabo una breve caracterización del escenario científico que se desarrolló en este intervalo de ciento veinte años y sus principales relaciones con el contexto social más amplio de la época, señalando lo que, tal vez, podría ser la raíz del sueño histórico de las concepciones de Jean Itard, a saber, la hegemonía de la doctrina del determinismo biológico.

Palabras clave: Niño. Discapacidad. Determinismo Biológico. Itard. Vigotski. 


\section{Introdução}

O presente ensaio tem como objetivo apresentar alguns fatos que, talvez, possam lançar alguma luz para a compreensão do hiato histórico que há entre dois estudiosos que se ocuparam da educação de crianças com deficiência. São eles: Jean-Marc-Gaspard Itard e Lev Semionovitch Vigotski.

Jean Itard nasceu na cidade de Provençal, no sul da França, em 1774 e faleceu em Paris, no ano de 1838. Trabalhava como médico no Instituto Nacional de Surdos-Mudos, local em que pode conhecer e atuar junto ao garoto Victor, comumente referido como o Selvagem de Aveyron. Itard celebrizou-se por essa atuação. Desenvolveu, junto ao menino, um programa pedagógico extremamente criativo, criterioso e avançado para a época. Todavia, esse trabalho não teve a repercussão que merecia. Ao contrário, conforme apontam Banks-Leite e Galvão (2000), sofreu "sucessivos eclipses seguidos de redescobertas" (p. 18), sendo que estas foram sempre pontuais e nunca causaram grande entusiasmo ou tiveram repercussões importantes. Itard (2000 $a$ e $b$ ) apresentou dois relatórios sobre sua atuação com Victor - um, em 1801 e outro, em 1806 - em que descreve detalhadamente os procedimentos que empregou na educação do garoto, os resultados que obteve e suas principais conclusões. Contudo, como indica Cordeiro (2006):

Muitas vezes, foi mesmo sugerido que este foi um trabalho de menor importância, por ter acrescentado pouco à teoria da educação. De fato, Itard não elaborou nenhum sistema teórico que contemplasse conceitos como desenvolvimento, educação e afetividade. Seus conhecimentos derivaram, nesse caso, de uma prática reflexiva, que buscava todo o tempo manter a difícil tensão entre teoria e prática. (p. 182).

Terá sido essa a única razão do esquecimento histórico das contribuições importantes de Jean Itard para a educação de crianças e jovens com deficiência?

Duzentos e vinte anos separam-nos das realizações desse ilustre médico-pedagogo. Passado tanto tempo, elas ainda são surpreendentes, apesar de vivermos em uma época com muito mais recursos científicos e tecnológicos para diagnóstico, tratamento e educação de crianças com desenvolvimento atípico do que aquela em que ele viveu. Junte-se a isso o fato de terem se passado aproximadamente cento e vinte anos, desde os trabalhos de Itard, para que
* Doutorado em Psicologia pela Universidade de São Paulo. Pesquisadora associada da Universidade de Brasília e professora do Centro Universitário de Brasília.

Email: bethtunes@ gmail.com

** Doutoranda do PPGE da Universidade de Brasília.

Email: souzapaline1@gmail.com 
houvesse a apresentação de um sistema teórico que incorporasse a uma teoria geral do desenvolvimento psicológico a importante questão do desenvolvimento atípico. Isso ocorreu com os trabalhos de Lev Semionovitch Vigotski, na União Soviética, nas primeiras décadas dos anos de 1900.

Vigotski nasceu em Orsha, na Região de Vitebskaia, em 1896, na Bielorrússia. Um ano depois, sua família, mudou-se para a cidade de Gomel. Em 1913, concluiu os estudos no ginásio; em 1914, ingressou na Faculdade de Medicina da Universidade Imperial de Moscou e, simultaneamente, na Faculdade de História e Filosofia da Universidade Popular Chaniavski, época em que começou a dedicar-se aos estudos de Psicologia (ver PRESTES, 2012). Entre 1916 e 1922, dedicou-se a trabalhos sobre literatura (ver VIGOTSKI, 2015; PRESTES; e TUNES, 2011).

Em 1919, Gomel foi libertada da ocupação alemã e ele começou a realizar tarefas práticas ligadas à instrução popular e também a lecionar Psicologia. Em 1924, mudou-se para Moscou e, a partir de então, dedicou-se aos estudos na área da Defectologia até 1934, quando faleceu.

Muitos desses trabalhos foram reunidos e publicados no Tomo V das Obras Escogidas, pela Editora Visor de Madrid com o título Fundamentos de Defectología. Esses textos constituem uma síntese de ideias de vários estudiosos e teóricos anteriores e coetâneos de Vigotski. As ideias expostas não eram hegemônicas no momento histórico em que foram elaboradas e, com toda clareza, opunham-se à ideologia racista então vigente ( TUNES 2017).

Muito se fez, na União Soviética, para que suas obras não fossem publicadas e divulgadas. Elas foram adormecidas por cerca de vinte anos após sua morte e despertadas em 1955, quando Aleksandr Romanovitch Luria e Aleksei Nikolaievitch Leontiev envidaram esforços para a publicação e republicação dos trabalhos dele.

Atualmente, Vigotski é bastante publicado em seu país e em todo mundo há inúmeros estudiosos dedicados a compreender e divulgar suas ideias. No Brasil, o acesso a obras de Vigotski começou, aproximadamente, a partir dos anos de 1980 (PRESTES, 2012).

Apresentam-se, a seguir, uma síntese de ideias de Jean Itard e de Lev Semionovitch Vigotski com o intuito de se mostrar algumas similaridades que existem entre elas.

\section{Desenvolvimento}

\section{Jean-Marc-Gaspard Itard}

Em janeiro de 1800, um menino selvagem foi encontrado na casa de um tintureiro, no Cantão de Saint Sernin, França, para onde se dirigira, espontaneamente, buscando 
aquecer-se junto ao fogo, num dia do rigoroso inverno daquele ano. Alguns meses antes, havia sido capturado por caçadores que o abrigaram e alimentaram por cerca de uma semana até sua fuga. Após ser encontrado na casa do tintureiro, autoridades do Departamento de Aveyron informaram Paris sobre a captura de um garoto que aparentava ter entre 12 e 15 anos, era mudo e parecia surdo. Num primeiro momento, foi levado para uma instituição destinada a doentes e indigentes, o Asilo de Saint-Affrique. Após um mês, foi encaminhado para a Escola Central de Rodez e examinado pelo professor de História Natural, Bonaterre. Pouco tempo depois, este professor o conduziu ao Instituto Nacional de Surdos-mudos, local em que foi examinado pelo médico Philippe Pinel (1745-1826), entre outros homens ilustres, cujo relatório concluía que o garoto teria sido abandonado por ser idiota e que não havia qualquer esperança quanto à possibilidade de educá-lo. Contudo, Jean-Marc-Gaspard Itard, discípulo de Pinel, discordou de seu mestre, após examinar o menino, entendendo que seria possível educá-lo e integrá-lo à sociedade. Ele supunha que o estado em que o menino se encontrava era devido à privação de contato social (BANKS-LEITE e GALVÃO, 2000).

A convicção de Itard era a de que "o homem não nasce como homem mas é construído como homem" (PESSOTTI, 2012, p.44), ou seja, para ele, não havia uma deficiência biológica, mas uma insuficiência cultural.

Itard (2000 $a$ ) iniciou com Victor, nome que deu ao selvagem de Aveyron, um processo de educação tendo como primeiro objetivo ligá-lo à vida social. Sem isso, entendia que sua educação não seria possível. No princípio, utilizou-se das atividades preferidas do garoto para ensiná-lo, selecionando, gradualmente, hábitos que favoreciam as práticas de adequação às suas deficiências. Na segunda etapa, o objetivo do trabalho passou a ser o de compensar as deficiências sensoriais por intermédio de intensa estimulação, explorando uma aquisição como condição para outra. Após três meses de trabalho, Itard relatou que Victor desenvolveu consideravelmente os sentidos do tato, do olfato e os gestos, demonstrando ainda dificuldade na visão e audição e, ao final do programa de trabalho, o garoto era capaz de compreender conceitos de objetos e suas funções, a relação entre palavras e ainda progrediu na aquisição de sentimentos e emoções e nas manifestações de afeto em situações diversas. No entanto, Itard admitiu que, em função da inexistência quase total da audição e da fala, a educação de Victor não se realizaria por completo e que o período de inatividade intelectual afetara seu desenvolvimento, tornando-o lento e penoso.

Conforme analisa Pessotti (2012), para Itard, a educação especial não era simplesmente uma questão de se 
elaborar um método universal, um modelo de procedimento, um modelo único. Ela seria condicionada pelos limites que a ontogênese impõe ao educando e significa, antes de tudo, individualização e não universalização, isto é, há a necessidade imperativa de ajustamento de programas às peculiaridades do aluno como "pessoa com desejos, aversões, interesses e inércias" (PESSOTTI, 2012, p. 58); o "método de educação foi criado para Victor segundo suas motivações, sucessos e limitações" (p. 58) e deve-se levar em conta que isso não foi feito por Itard devido à carência de experiências conhecidas até então, mas em decorrência de sua posição "filosófica ante o ser humano, diante do educando e frente ao organismo biológico a ser posto em funcionamento adequado" (p. 58). Pessotti (2012) acrescenta que ele via a deficiência mental no contexto de um processo de desenvolvimento, com fases e estágios encadeados "como se o desenvolvimento fosse uma contínua gênese de operações e desempenhos mais complexos e refinados a partir de aquisições preliminares" (p. 61). Vê-se que Itard adotava um ponto de vista genético-cultural para referir-se ao processo de desenvolvimento.

Em dois relatórios escritos, um em 1801 e outro em 1806, Itard (2000a, 2000b) descreveu o programa das ações realizadas com Victor e seus mais importantes resultados. Pessotti (2012) chama a atenção para a atualidade dos procedimentos descritos: "a cada passo do texto de 1801 o leitor se depara com afirmações de conteúdo tão moderno que Itard se afigura, cada vez mais, um gênio da pedagogia" (p. 60). A leitura de seus relatórios permite constatar o modo intencional e metódico de atuar, as interpretações criativas que realizava dos resultados que obtinha, fossem positivos ou negativos, os modos como fazia correções de rota e, além disso, conhecer alguns dos princípios que guiavam suas ações.

Eis aqui uma síntese das importantes conclusões a que Itard chegou após apenas nove meses de trabalho com Victor:
1. Que o homem é inferior a grande número de animais no puro estado de natureza ${ }^{1}$; estado de nulidade e de barbárie, que sem fundamento revestiam das mais sedutoras das cores; estado no qual o indivíduo, privado das faculdades características de sua espécie, vegeta miseravelmente, sem inteligência bem como sem afeições, numa vida precária e reduzida apenas às funções da animalidade.

2. Que essa superioridade moral, que se diz ser natural ao homem, é apenas o resultado da civilização que o eleva acima dos outros animais por um grande e potente móbil. Esse
1 Nesse momento de seu relatório, apresenta a seguinte nota de rodapé: "Não tenho dúvidas que, se isolassem, já na primeira idade, duas crianças, uma macho e a outra fêmea e que se fizesse o mesmo com dois quadrúpedes escolhidos na espécie menos inteligente, estes últimos se mostrassem muito superiores (sic) às primeiras nos meios de suprir as suas necessidades e de zelar seja por sua própria conservação, seja pela de seus filhos" (ITARD, 2000a). 
móbil é a sensibilidade predominante de sua espécie; propriedade essencial da qual decorrem as faculdades imitativas e a tendência contínua que o força a procurar em outras necessidades sensações novas.

3. Que essa força imitativa destinada à educação de seus órgãos, sobretudo à aprendizagem da fala, muito enérgica e muito ativa nos primeiros anos de vida, se enfraquece rapidamente com os progressos da idade, com $\mathrm{o}$ isolamento e todas as causas que tendem a embotar a sensibilidade nervosa; [...]

4. Que existe no mais isolado selvagem, bem como no citadino elevado ao mais alto ponto de civilização, uma relação constante entre suas ideias e suas necessidades [...] (ITARD, 2000a, p. 175-176, itálicos do próprio autor).

Ele conclui seu relatório de modo tão interessante que é impossível resistir à transcrição de suas palavras:

Tive também aqui de não me apressar em julgar e concluir; persuadido de que não se pode deixar amadurecer demais pelo tempo e confirmar com observações posteriores, todas as considerações que tendem a destruir preconceitos, talvez respeitáveis, e tanto as mais doces como as mais consoladoras ilusões da vida social. (ITARD, 2000a, p. 177).

\section{Lev Semionovitch Vigotski}

Conforme já foi dito, na segunda e terceira décadas do século XX, L. S. Vigotski (1997) dedicou-se, entre as suas inúmeras realizações, ao estudo dos processos de desenvolvimento de crianças com deficiência de origem orgânica. Para ele, o desenvolvimento constitui-se como um processo orgânico e psicológico de criação e recriação da personalidade da criança e que, quando esta apresenta alguma deficiência fisiológica, o seu desenvolvimento não se torna anormal. O que se observa, de fato, é o desenrolar de um processo atípico, em comparação ao que é o mais comum, mas que segue as mesmas leis que regem o desenvolvimento de todas as crianças.

A tese de Vigotski sobre o desenvolvimento de crianças que apresentam defeitos orgânicos é a de que não se trata de crianças menos desenvolvidas que outras. Elas se desenvolvem de modos diferentes. A rigor, para ele, não há um padrão de desenvolvimento que seria próprio da maior parte das crianças e outros modos distintos que seriam, por não se tratarem dos mais comuns, anormais. Cada ser humano que habitou, habita e habitará o planeta teve, tem 
ou terá um modo próprio, peculiar, individual de desenvolver-se. Assim como nossas impressões digitais, há sempre uma particularidade, uma diferença, por menor que seja, no processo de desenvolvimento de cada ser humano.

Assumindo essa premissa, ele define, então, a principal tarefa que o estudioso teria diante de si: seria necessário compreender por que existe tamanha diferenciação nos processos de desenvolvimento e que diferenças são essas. Ao fazer isso, ele subverte a lógica que existia em sua época: não se trataria de buscar o que é comum nos processos de desenvolvimento e identificar e descrever o que é diverso do padrão, visando a buscar formas de eliminar essa diversidade e fazê-la voltar ao leito comum. Essa é uma realização inatingível, pois cada ser humano é um acontecimento concreto singular, irreprodutível em sua unicidade. O mundo concreto é assim: sequer existem duas pedras iguais; por mais semelhantes que sejam, há sempre um sinal, ainda que, aparentemente insignificante, que as faz diferirem entre si.

O processo de desenvolvimento cultural da criança, como Vigotski (2018) o denominou, acontece mediante a unidade de influências hereditárias e do meio, unidade esta, que, por sua vez, não é constante, permanente ou invariante, além de não consistir de uma combinação mecânica dos dois fatores. Por isso, o processo de desenvolvimento é dinâmico: a cada nova formação altera-se a correlação entre as funções, reestruturando-se as relações entre diferentes funções da personalidade. Em cada idade, algumas particularidades orgânicas da criança assumem o centro do desenvolvimento, indicando que cada uma delas possui um período propício para desenvolver-se. Cada idade representa etapas específicas no desenvolvimento e as novas qualidades que surgem são preparadas pelo período precedente, configurando uma relação entre o presente e o passado, orientada para o futuro, isto é, a emergência de novas formações, um processo intrinsecamente criativo:

desenvolvimento é um processo de formação do homem ou da personalidade que acontece por meio do surgimento, em cada etapa, de novas qualidades, novas formações humanas específicas, preparadas por todo curso precedente, mas que não se encontram prontas nos degraus anteriores (VIGOTSKI, 2018, p. 36).

Ainda que sejam as mesmas as leis que regem o desenvolvimento cultural da criança comum em relação à que apresenta alguma deficiência, nesta, essas leis apresentam uma expressão concreta qualitativamente diversa e mais claramente discernível, uma correlação marcadamente singular entre as regularidades sociais e as biológicas. 
Daí porque o estudo do desenvolvimento cultural atípico é da maior importância também por lançar luz indispensável para a compreensão do desenvolvimento cultural das crianças comuns. Na verdade, aqui, é importante afirmar que a ideia de peculiaridade qualitativa do desenvolvimento cultural é o centro metodológico das formulações teóricas de Vigotski.

Se há alguma dificuldade na educação da criança com deficiência, ela não se encontra, primariamente, na compreensão das repercussões dessa peculiaridade orgânica no seu processo de desenvolvimento cultural, mas no modo como se define o lugar social de sua deficiência. Em nossa sociedade, é hegemônica a ideia de que o mundo é constituído de perfeições e imperfeições. A cegueira, por exemplo, é tratada como uma imperfeição. Por isso, é indesejável e fere o ideal de uma sociedade de homens perfeitos. Assim, em geral, as ações prioritárias voltam-se para a cura ou a atenuação da deficiência e não para a organização do ambiente social de modo a proporcionar à criança com deficiência as melhores condições sociais possíveis para o seu desenvolvimento. Por isso, não se leva em conta que a natureza do processo educativo é a mesma, tenha ou não a criança alguma deficiência. Por isso, as intervenções médicas e educativas voltam-se muito mais para corrigir o defeito do que para tirar dele o melhor proveito para o desenvolvimento pleno da criança, como se verá a seguir.

Assim como para um organismo in natura o desenvolvimento é orientado pela exigência de adaptação às condições que a natureza apresenta, o desenvolvimento cultural também o é pelo imperativo de adaptação social que Vigotski denominou de compensação social (TUNES, 2017). Qualquer defeito ou deficiência não se limita à perda isolada de uma função. Isso implica a reorganização da personalidade como um todo e uma nova configuração das relações entre funções que põem em atividade novas forças psíquicas. A criança com deficiência têm esse fato a seu favor, o que lhe possibilita reagir às dificuldades causadas pelo impacto social de sua deficiência. No processo de adaptação ao meio, ela pode desenvolver funções por meio das quais compensa, equilibra ou supera a deficiência orgânica.

É bastante fácil constatar a existência de alguma deficiência na criança. Que dificuldade há em verificar que uma criança não enxerga, não ouve ou que apresenta alguma forma de comportamento que diverge do que é o mais comum, por exemplo? Nenhuma. A despeito disso, a criança é levada ao especialista que, então, a examina, aplica-lhe testes, avalia seu desempenho escolar, etc. e, em função do que observou, apresenta um nome - muitas vezes, incompreensível para o leigo -, dizendo aos pais ser 
esse o diagnóstico. Não se vê, contudo, o mesmo empenho e ações correspondentes voltadas, prioritariamente, para o objetivo de encontrar as formas de ações práticas e educativas para que seja superado o que se diagnosticou. Vigotski (1997), há quase cem anos, já chamara a atenção para esse fato. Para ele, a dificuldade se encontraria, exatamente, na identificação da estrutura e da dinâmica do defeito e na determinação de quais seriam os processos que poderiam surgir no processo de desenvolvimento da criança e levariam à superação da deficiência.

$\mathrm{Na}$ criança, os órgãos deficientes entram em luta com o mundo exterior ao qual devem adaptar-se. Ao mesmo tempo em que esta luta é acompanhada por uma carga excessiva de morbidade e até de mortalidade também são produzidas elevadas possibilidades de compensação. Por essa razão, é necessário que se desvie o foco da enfermidade para a possibilidade de superação da mesma, identificando o lugar que a insuficiência ocupa no sistema da personalidade da criança e que tipo de reestruturação está sendo produzida em resposta à dificuldade social advinda do defeito. Logo, o que se caracteriza como fonte do surgimento de processos compensatórios são exatamente as dificuldades reais com as quais a criança lida no seu processo de relação com o meio social. Segundo Vigotski (1997):

[...] o destino dos processos compensatórios e dos processos de desenvolvimento em seu conjunto depende não só do caráter e da gravidade do defeito, mas também da realidade social do defeito, quer dizer, das dificuldades a que leva o defeito desde o ponto de vista da posição social da criança (p. 136)

Assim sendo, o processo compensatório se vincula à somatória das reservas construídas na vida social coletiva, à sociabilidade da conduta e à tendência própria de cada criança.

O processo de desenvolvimento cultural, na visão de Vigotski (1997), consiste basicamente no domínio de instrumentos culturais criados pela humanidade no processo de desenvolvimento histórico. O emprego desses instrumentos modifica o curso e a estrutura das funções psicológicas. O que determina o tipo de desenvolvimento cultural da criança deficiente é, exatamente, a possibilidade de ela se utilizar dos instrumentos culturais, dominando-os, para conduzir, regular, orientar ou direcionar suas próprias funções psíquicas (memória, percepção, atenção, pensamento, vontade, emoção, etc.). Quando nos deparamos com uma tarefa que supera as possibilidades naturais de uma função, podemos nos utilizar de processos artificiais de combinação, imaginação, pensamento ou outros que podem 
conjugar-se, em diferentes graus, com outras funções, criando quadros singulares de desenvolvimento. Todavia, para que isso aconteça é imprescindível a vivência na coletividade. O princípio formativo das funções psíquicas superiores encontra-se na transformação de formas coletivas de colaboração em formas individuais de conduta, como acontece no processo de desenvolvimento da fala, que, inicialmente, tem como fim a comunicação social (a fala para o outro) até se transformar em meio fundamental de pensamento. Outro exemplo é o desenvolvimento do autodomínio de processos volitivos que surge e se manifesta, inicialmente, sob a forma coletiva de atividade, nos jogos com regras, por exemplo, para depois se manifestar como autorregulação. Da conduta coletiva, da colaboração entre criança e pessoas do seu convívio, de sua experiência social, desenvolvem-se as funções superiores. Daí decorre que, para Vigotski (1997), toda educação tem um caráter de educação social.

Não obstante, quando se fala do papel da coletividade no desenvolvimento da criança, Vigotski (2018) alerta para o fato de que não se deve estudar o meio como um ambiente que, por conter determinadas qualidades, define, diretamente, seu desenvolvimento. Ele deve ser analisado sob o ponto de vista da relação que guarda com a criança em uma determinada fase de seu desenvolvimento, pois o papel de cada um de seus elementos modifica-se nos vários degraus etários. Ou seja, é preciso levar em conta a vivência da criança - unidade entre a personalidade e o meio social (VIGOTSKI, 1995; PERGAMENSCHIK, 2017).

Pelo que se disse, o objetivo geral da escola que atende a crianças com alguma deficiência é a de que elas tenham um lugar no convívio social. Essa é a visão de Vigotski (1997). Se o defeito se constitui como tal no plano da vida social, conforme já afirmado, ou seja, se o defeito trata-se como um desvio social, então, obviamente, também a compensação somente pode realizar-se no plano social. A educação da criança deficiente deve, assim, basear-se em uma elevada noção da personalidade humana, na compreensão de sua unidade e integridade orgânica, sendo a plena validez social o ponto final da educação, a conquista de uma posição social. Desse modo, o processo de compensação social é determinado inteiramente por duas forças: as exigências sociais que se apresentam ao desenvolvimento e à educação da criança e suas forças psicológicas intactas. A reserva de compensação é, em grande medida, a vida social coletiva da criança, na qual se encontra o material para construção das funções autorreguladas que se originam no processo de compensação social. Vigotski apresenta uma perspectiva inovadora na medida em que não invalida o ser humano com alguma deficiência. Ao contrário, esmerou-se 
na defesa da possibilidade de desenvolvimento cultural de todos os seres humanos, ainda que por caminhos distintos dos mais comuns.

\section{Considerações finais que são esperadas como provisórias}

Retomando o que se disse ao início deste texto, pouco mais de cem anos separam Itard de Vigotski. É tentador especular acerca do hiato que existe entre a publicação dos relatórios de Itard e os trabalhos de Vigotski. O que teria acontecido nesses cem anos em que a pedagogia criativa de Itard foi praticamente esquecida? Pelas conquistas prodigiosas que foram atingidas por Victor de Aveyron, não seria esperado que o que fora feito tivesse se difundido na sociedade e viesse a ser investigado e aplicado a diversas esferas da educação, especialmente as que envolviam crianças e jovens que apresentavam deficiências das mais diferentes ordens? Pelo menos, era essa a expectativa de Dacier, secretário da classe de história e de literatura antiga do Institut de France, ao encaminhar ao Ministro do Interior, em 1806, o relatório de Itard. Disse ele:

O relatório do Sr. Itard contém, aliás, a exposição de uma série de fenômenos singulares e interessantes, de observações perspicazes e judiciosas, e apresenta uma combinação de procedimentos instrutivos apropriados para fornecer novos dados à ciência e cujo conhecimento só poderia ser extremamente útil a todas as pessoas que se dedicam à educação da juventude ((ITARD, 200ob, p. 181).

Nesse relatório, Itard já apontava sinais de que suas iniciativas começavam a ser esquecidas:

Falar-lhe do Selvagem do Aveyron é reproduzir um nome que hoje já não inspira nenhuma espécie de interesse; é lembrar um ser esquecido por aqueles que se limitaram a vê-lo e desdenhado por aqueles que acreditaram julgá-lo. Para mim, que me ative até agora a observá-lo e a prodigalizar-lhe meus cuidados, muito indiferente ao esquecimento de uns e ao desdém dos outros, estribado em cinco anos de observações diárias, venho fazer a Vossa Excelência o relatório que ela espera de mim, contar-lhe o que vi e o que fiz, expor o estado atual desse rapaz, as vias longas e difíceis pelas quais foi conduzido e os obstáculos que transpôs, bem como os que não pôde superar (ITARD, 200ob, p. 183, itálicos do próprio autor). 
Sabe-se que o século XVIII foi o berço de ideias que afirmavam ser a sociedade um reflexo fiel da biologia. Trata-se da versão científica de uma ideologia racista que surgiu com força e veio a se desenvolver em todos os países ocidentais no decorrer do século XIX (ARENDT, 2012), embasando muitos acontecimentos do início do século XX, especialmente, os ligados às duas grandes guerras. Na verdade, o aspecto científico dessa ideologia é secundário, pois ela foi "criada, mantida e aperfeiçoada como arma política e não como doutrina teórica” (ARENDT, 2012, p. 235). Gould (1991) refere-se a essa doutrina como determinismo biológico. Segundo a mesma, a falta de personalidade, de tato, de produtividade, de inteligência ou de algum atributo socialmente valorizado é inata e isso permite distinguir entre pessoas superiores e inferiores (ARENDT, 2012). Assim, surgiu a ideia de quantificação de atributos socialmente valorizados, escalonando-se as pessoas e criando-se uma visão simplificadora do mundo social conforme a qual elas seriam melhores ou piores que outras (TUNES, 2017).

Pode-se dizer que o século XIX foi a era da fascinação pelos números e, aliada à ideia de evolução, a quantificação na ciência forjou a primeira teoria científica racista de peso (GOULD, 1991). Esse foi o século de Francis Galton, alcunhado por Gould (1991) de apóstolo da quantificação, que acreditava que qualquer coisa poderia ser mensurada, "que inventou o termo eugenia, em 1883, e defendeu a regulamentação do matrimônio e do tamanho das famílias de acordo com o patrimônio hereditário dos pais" (p. 67). A quantificação era o deus de Galton que mantinha "a firme convicção de que quase tudo o que podia medir tinha uma caráter hereditário” (p. 68). Esse foi o século de Paul Broca (1824-1880), que, em 1861, afirmou que "Em geral, o cérebro é maior nos adultos que nos anciões, no homem que na mulher, nos homens eminentes que nos homens medíocres, nas raças superiores que nas inferiores" (citado por GOULD, 1991, p. 76). Esse foi o século em que nasceu Stanley Hall (1846-1924), psicólogo estadunidense que defendia que havia maior suicídio entre as mulheres porque elas se encontravam em estágio evolutivo inferior aos homens (GOULD, 1991). Enfim, esse foi o século em que o verdadeiro verme que alimentaria o Holocausto nasceu, criou-se, engordou e procriou-se: a ideia de que há homens piores ou melhores que outros. Eis o verdadeiro verme destruidor.

Não é de se estranhar, pois, que concepções e ações como as de Itard sofressem solução de continuidade e não se disseminassem. Afinal, naquele século, os alimentos alimentavam outras ideias, enquanto aquelas eram adormecidas. Todavia, o que adormeceu pode acordar. E assim foi que, talvez por um capricho da história, retomou-se o 
caminhar interrompido com um outubro vermelho do qual ressurgiram renovadas, atualizadas, fortalecidas e teoricamente adensadas aquelas ideias tão caras a todos nós que sabemos da importância de uma ciência forjada por mentes despidas de preconceitos e bem vestidas de muita humanidade. Havia uma esperança no ar que, agora, quase cem anos após a morte de Vigotski, parece começar a se desfazer com a restauração de ideias e práticas que voltam a nos ameaçar a todos. Os vermes voltaram!!!

\section{Referências}

ARENDT, Hannah. Origens do totalitarismo. Tradução de Roberto Raposo. São Paulo: Companhia das Letras, 2012.

BANKS-LEITE, Luci e GALVÃO, Isabel. Uma introdução à história de Victor do Aveyron e suas repercussões. Em BANKS-LEITE, Luci e GALVÃO, Isabel (Orgs.). A educação de um selvagem - as experiências pedagógicas de Jean Itard. São Paulo: Cortez, 2000, p. 11-24.

CORDEIRO, Aliciene Fusca Machado. Relações entre educação, aprendizagem e desenvolvimento humano: as contribuições de Jean-Marc-Gaspard Itard (1774-1838). Tese de Doutorado, Pontifícia Universidade Católica de São Paulo, 2006, 209 p.

GOULD, Stepehn Jay. A falsa medida do homem. Tradução de Válter Lellis Siqueira. São Paulo: Martins Fontes, 1991.

ITARD, Jean-Marc-Gaspard. Relatório I: Da educação de um homem selvagem ou dos primeiros desenvolvimentos físicos e morais do jovem Selvagem do Aveyron. Em BANKS-LEITE, Luci e GALVÃO, Isabel (Orgs.). A educação de um selvagem - as experiências pedagógicas de Jean Itard. São Paulo: Cortez, 2000a, p. 123-177.

ITARD, Jean-Marc-Gaspard. Relatório I: Relatório feito a Sua Excelência o Ministro do Interior sobre os novos desenvolvimentos e o estado atual do Selvagem do Aveyron. Em BANKS-LEITE, Luci e GALVÃO, Isabel (Orgs.). A educação de um selvagem - as experiências pedagógicas de Jean Itard. São Paulo: Cortez, 200ob, p. 179-229.

PERGAMENSCHIK, Leonid. A concepção de vivência em L. S. Vigotski: do conhecimento conjunto à superação da solidão. VERESK - Cadernos Acadêmicos Internacionais, Brasília: UniCEUB, v.1.p. 35-46, 2017. Disponível em: <http://repositorio.uniceub.br/bitstream/235/11339/3/ VERESK\%20\%281\%29.pdf>. Acesso em: 24. Abril. 2019. 
PESSOTTI, Isaías. Deficiência mental: da superstição à ciência. Marília: ABPEE, 2012.

PRESTES, Zoia. Quando não é quase a mesma coisa - traduções de Lev Semionovitch Vigotski no Brasil. Campinas, SP: Autores Associados, 2012.

TUNES, Elizabeth. A Defectologia de Vigotski - uma contribuição inédita e revolucionária no campo da educação e da psicologia. VERESK - Cadernos Acadêmicos Internacionais - Estudos sobre a perspectiva histórico-cultural de Vigotski - Brasília: UniCEUB, 2017, p. 75-84.

VIGOTSKI, Lev Semionovitch. Obras Escogidas. Tomo IV. Psicologia Infantil. Tradução de Lídia Kuper. Madrid: Visor, 1995.

VIGOTSKI, Lev Semionovitch. Obras Escogidas. Tomo V. Fundamentos da defectologia. Tradução de Julio Guillermo Blank. Madrid: Visor, 1997.

VIGOTSKI, Lev Semionovitch. Polnoe sobranie sotchineni.Tom $I$. Moskva: Lev, 2015.

VIGOTSKI, Lev Semionovitch. Sete aulas de L.S. Vigotski sobre os fundamentos da pedologia. Em Prestes, Zoia e Tunes, Elizabeth (Orgs.). Rio de Janeiro: E-Paper, 2018. 